\title{
Hubungan Bimbingan Belajar dan Disiplin Belajar Dengan Kemampuan Memecahkan Soal Cerita Matematika Kelas VI di SDN 2 Muara Ciujung Barat
}

\author{
Neneng Yatini, Sholeh Hidayat dan Suroyo \\ ${ }^{1,3}$ Universitas Terbuka, Indonesia \\ ${ }^{2}$ Universtas Tirtayasa, Indonesia \\ Email authors: nnk.yatini@gmail.com/sholeh.hidayat@untirta.ac.id/
}

suroyo@ecampus.ut.ac.id

\begin{abstract}
ABSTRAK
Penelitian ini dilakukan dengan tujuan untuk menganalisa hubungan bimbingan belajar dan disiplin belajar dengan kemampuan memecahkan soal cerita matematika kelas VI Sekolah Dasar. Penelitian ini merupakan penelitian kuantitatif korelasional. Populasi dalam penelitian ini adalah seluruh siswa kelas VI di SDN 2 Muara Ciujung Barat, sempel diambil berjumlah 39 orang. Teknik pengumpulan data menggunakan angket yang telah diuji validitas dan perhitungan reliabilitas. Berdasarkan hasil perhitungan didapatkan hasil penelitian sebagai berikut (1) Terdapat hubungan yang sangat kuat dan positif bimbingan belajar dengan kemampuan memecahkan soal cerita matematika pada siswa kelas VI di SDN 2 Muara Ciujung Barat dihubungkan dan ditentukan oleh bimbingan belajar sebesar 78,0\% sedangkan sisanya ditentukan oleh faktor lain. (2) Terdapat hubungan yang sangat kuat dan positif disiplin belajar dengan kemampuan memecahkan soal cerita matematika pada siswa kelas VI di SDN 2 Muara Ciujung Barat dihubungkan dan ditentukan oleh disiplin belajar sebesar 63,0 \%, sedangkan sisanya ditentukan oleh faktor lain. (3) Terdapat hubungan yang kuat dan positif bimbingan belajar dan disiplin belajar secara bersama-sama dengan kemampuan memecahkan soal cerita matematika kelas VI di SDN 2 Muara Ciujung Barat sebesar 80,8\%, sedangkan sisanya ditentukan oleh faktor lain. Kesimpulan dari penelitian ini adalah menyatakan bahwa terdapat hubungan yang kuat dan positif bimbingan belajar dan disiplin belajar secara bersama-sama dengan kemampuan memecahkan soal cerita matematika Kelas VI di SDN 2 Muara Ciujung Barat.
\end{abstract}

Kata Kunci: bimbingan belajar, disiplin belajar dan kemampuan memecahkan soal cerita matematika

\section{ABSTRACT}

This study was conducted with the aim of analyzing the relationship between tutoring and learning discipline with the ability to solve math story problems for grade VI Elementary School. The population in this study were all sixth grade students at SDN 2 Muara Ciujung Barat, the sample was taken using a saturated sample of 39 people. The data collection technique uses a questionnaire that has been tested for validity and reliability calculations. Based on the calculation results, the research results are as follows (1) There is a very strong and positive relationship between tutoring and the ability to solve math story problems in grade VI students at SDN 2 Muara Ciujung Barat connected and determined by tutoring of $78.0 \%$ while the rest is determined by other factors. (2) There is a very strong and positive relationship between learning discipline and the ability to solve math story problems in grade VI students at SDN 2 Muara Ciujung Barat linked and determined by learning discipline by $63.0 \%$, while the rest is determined by other factors. (3) There is a strong and positive relationship between 
tutoring and learning discipline together with the ability to solve math story problems for grade VI at SDN 2 Muara Ciujung Barat by $80.8 \%$, while the rest is determined by other factors. The conclusion of this study is that there is a strong and positive relationship between tutoring and learning discipline together with the ability to solve math story problems for Class VI at SDN 2 Muara Ciujung Barat.

Keywords: tutoring, learning discipline and ability to solve math story problems.

\section{PENDAHULUAN}

Pendidikan sangat penting bagi kehidupan. Setiap manusia memiliki hak yang sama untuk mendapatkan pendidikan yang layak sesuai dalam UU No. 20 Tahun 2003 tentang sistem Pendidikan Nasional, di jelaskan bahwa Pendidikan merupakan usaha sadar dan terencana untuk mewujudkan suasana belajar dan proses pembelajaran, agar peserta didik secara aktif mengembangkan potensi dirinya untuk memiliki kekuatan spritual keagamaan, pengendalian diri, kepribadian, kecerdasan, akhlak mulia, serta keterampilan yang di perlukan dirinya, masyarakat, bangsa dan negara.

Pendidikan dikatakan berhasil apabila dapat mencapai hasil sesuai tujuan pendidikan nasional yang telah di tetapkan. Tujuan pendidikan nasional yang hendak dicapai merupakan tanggung jawab bersama antara sekplah, keluarga dan masyarakat. Karena pada dasarnya pendidikan dapat di peroleh dari lingkungan keluarga, sekolah maupun lingkungan masyarakat.

Matematika mempunyai peranan yang penting dalam dunia pendidikan. Peranan tersebut dikembangkan dalam dimensi perkembangan anak, masyarakat dan dunia kerja, maka matematika digunakan dari tingkat pendidikan terendah hingga tertinggi. Dari zaman dahulu sampai saat ini matematika digunakan untuk membantu mendapatkan penyelesaian permasalahan kehidupan sehari-hari. Pengembangan kurikulum matematika ditekankan pada desain, implementasi dan disiplin untuk menunjang kebutuhan perkembangan anak yang sesuai dengan tuntunan perkembangan zaman yang berdampak pada tuntunan yang ingin dicapai dari kemampuan dasar matematika (cenceptual understanding, procedural fluency, productive dispotion, strategic, dan adaptive reasoning) yang sangat dibutuhkan untuk meningkatkan kemampuan dalam memahami konsep dasar matematika yang dapat digunakan untuk melanjutkan studi jenjang yang lebih tinggi.

Berdasarkan deskripsi awal bahwa terdapat beberapa kelemahan pada diri anak kelas VI di SDN 2 Muara Ciujung Barat terutama pada Pelajaran Matematika khususnya dalam menyelesaikan memecahkan soal cerita matematika kelas VI di SDN 2 Muara Ciujung Barat, tentunya ini perlu intensitas terutama pada hubungan belajar dan disiplin baik oleh guru maupun siswanya itu sendiri, khususnya pada mata pelajaran matematika masih dapat dikatakan rendah, hal tersebut dapat dilihat dari hasil nilai ulangan akhir semester gasal yang masih banyaknya siswa yang mendapatkan nilai di bawah KKM. Disiplin belajar yang kurang optimal pada mata pelajaran matematika ini disebabkan salah satunya karena siswa kelas VI masih banyak yang kesulitan dalam materi perkalian dan memahami soal cerita pada pelajaran Matematika.

Oemar Hamalik (2004: 195) mengemukakan adalah bimbingan yang ditujukkan kepada siswa untuk mendapat pendidikan yang sesuai dengan kebutuhan, bakat, minat, kemampuannya dan membantu siswa untuk menentukan cara-cara yang efektif dan efisien dalam mengatasi masalah belajar yang dialami oleh siswa, sedangkan Menurut Ardi (2012), disiplin belajar adalah hal yang berpengaruh terhadap keberhasilan siswa, dengan demikian dapat dipahami 
bahwa disiplin belajar adalah mentaati tata tertib, atau kepatuhan dalam pemanfaatan waktu untuk belajar secara efektif dan efisien kemudian Sumarmo (2005:6-7) mengemukakan pemecahan masalah dapat dipandang dari dua sudut pandang yang berbeda yaitu sebagai pendekatan pembelajaran dan sebagai tujuan pembelajaran.

Dalam kesempatan ini rumusan yang ingin dicapai oleh peneliti yaitu Adakah hubungan bimbingan belajar dan disiplin belajar secara bersamasama dengan kemampuan memecahkan soal cerita Matematika kelas VI di SDN 2 Muara Ciujung Barat? Dengan tujuan penelitian adalah Untuk menganalisis dan mendeskripsikan hubungan bimbingan belajar dan disiplin belajar secara bersama-sama dengan kemampuan memecahkan soal cerita Matematika kelas VI di SDN 2 Muara Ciujung Barat.

\section{METODE}

Metode penelitian yang dilaksanakan pada penelitian ini dengan menggunakan metode kuantitatif korelasional, instrument pengumpulan data yang diperoleh dengan uji validitas dan perhitungan realibilitas, untuk uji validitas didapat melalui data primer maupun sekunder, data primer tersebut diolah melalui aplikasi SPSS versi 25.0, kriteria uji validitas adalah jika r tiap butir atau $r_{\text {hitung }}>r_{\text {tabel }}$ maka butir tersebut adalah valid. $r_{\text {tabel }}$ adalah $r=0,316$ dimana bila terdapat butir-butir yang tidak valid atau dibawah skor 0,316 maka harus dikeluarkan dahulu dari suatu variabel, butir lainnya yang tersisa akan dianalisis ulang kembali seperti langkah awal.

Selanjutnya perhitungan realibilitas melalui perhitungan instrument bimbingan belajar dan disiplin belajar diperoleh nilai alpha cronboach adalah 0,845. Berdasarkan perhitungan realibilitas jika nilai alpha cronboach lebih besar dari $r_{\text {tabel }}$ maka soal tersebut dikatakan realibel dan jika nilai alpha cronboach lebih kecil dari $r_{\text {tabel }}$ maka soal tersebut dikatakan tidak realibel. Nilai $t_{\text {tabel }}$ untuk $\mathrm{n}=39$ adalah $0,0,680$.

\section{HASIL DAN PEMBAHASAN}

\section{Uji Hipotesis}

\section{Hubungan Bimbingan Belajar dengan Kemampuan Memecahkan Soal Cerita} Matematika

Tabel 1. Nilai Koefisien Korelasi dan Determinasi Bimbingan Belajar Model Summary

\begin{tabular}{|c|c|c|c|c|}
\hline Model & $\mathbf{R}$ & R Square & $\begin{array}{l}\text { Adjusted R } \\
\text { Square }\end{array}$ & $\begin{array}{l}\text { Std. Error of the } \\
\text { Estimate }\end{array}$ \\
\hline 1 &, $883^{\mathrm{a}}$ & 0,780 & 0,774 & 3,389 \\
\hline
\end{tabular}

Predictors: (Constant), Bimbingan_Belajar

Koefisien korelasi (R) sebesar 0,883 menunjukkan hubungan yang kuat antara variabel Bimbingan Belajar dengan variabel Kemampuan Memecahkan Soal Cerita Matematika. Koefisien determinasi $\left(\mathrm{R}^{2}\right)$ sebesar 0,780 memberi pengertian bahwa 78,0 \% Variabel Kemampuan Memecahkan Soal Cerita Matematika ditentukan oleh Variabel Bimbingan Belajar, dan sisanya ditentukan oleh faktor lain. Std. Error of the Estimate merupakan kesalahan standar dari perkiraan yang bernilai 3,389 Dan nilai determinasi jauh dibawah standar kesalahan yang berarti koefisien korelasi Bimbingan Belajar dan Kemampuan Memecahkan Soal Cerita Matematika terdapat hubungan yang kuat. Untuk uji regresi 
Bimbingan Belajar dengan Kemampuan Memecahkan Soal Cerita Matematika melalui suatu persamaan dibawah ini :

Tabel 2. Persamaan Garis Regresi Bimbingan Belajar Dengan Kemampuan Memecahkan Soal Cerita Matematika

\section{Coefficients $^{\text {a }}$}

\begin{tabular}{|c|c|c|c|c|c|}
\hline Model & $\begin{array}{l}\text { Unstan } \\
\text { Coefi } \\
\text { B } \quad \mathrm{S}\end{array}$ & $\begin{array}{l}\text { zed } \\
\text { ts } \\
\text { ror }\end{array}$ & $\begin{array}{c}\text { Standardized } \\
\text { Coefficients } \\
\text { Beta }\end{array}$ & t & Sig. \\
\hline $1 \quad$ (Constant) & 13,145 & 3,661 & & 3,590 & 0,001 \\
\hline Bimbingan_Belajar & 1,401 & 0,122 & 0,883 & 11,439 & 0,000 \\
\hline
\end{tabular}

Dependent Variable: Kemampuan_Memecahkan_Soal_Cerita_Matematik

Berdasarkan tabel di atas maka didapatkan persamaan regresinya yaitu $: Y^{\wedge}=13,145+1,401$ $\mathrm{X}_{2}$ Dari persamaan regresi tersebut diatas diketahui bahwa koefisien regresi $\left(\mathrm{b}_{2}\right)$ sebesar 1,401 . Hal ini menunjukan besarnya Hubungan Bimbingan Belajar dengan Kemampuan Memecahkan Soal Cerita Matematika. Karena Hubungan tersebut bersifat positif Selanjutnya uji hipotesis Hubungan variabel bebas $\mathrm{X}_{2}$ dengan variabel terikat $\mathrm{Y}$ adalah dengan membandingkan antara $t_{\text {hitung }}$ dengan $t_{\text {tabel. }}$. Kriteria pengujiannya adalah apabila $t_{\text {hitung }}>t_{\text {tabel }}$ maka $\mathrm{H}_{0}$ ditolak dan $\mathrm{H}_{1}$ diterima. Sebaliknya apabila $\mathrm{t}_{\text {hitung }}<\mathrm{t}_{\text {tabel }}$, maka $\mathrm{H}_{0}$ diterima dan $\mathrm{H}_{1}$ ditolak. Dengan melihat hasil dari model persamaan regresi di atas, maka untuk menguji keberartian dari nilai koefisien regresi untuk variabel Bimbingan Belajar dapat digunakan dengan Uji-t, nilai thitung yang diperoleh yaitu sebesar 11,439 sedangkan t tabel yaitu sebesar 0,680. Sehingga $t_{\text {hitung }}>t_{\text {tabel }}$, maka hasil ini menunjukkan terdapat Hubungan variabel Bimbingan Belajar dengan variabel Kemampuan Memecahkan Soal Cerita Matematika.

\section{b. Hubungan Disiplin Belajar Dengan Kemampuan Memecahkan Soal Cerita Matematika}

Tabel 3. Nilai Koefisien Korelasi dan Determinasi Disiplin Belajar Model Summary

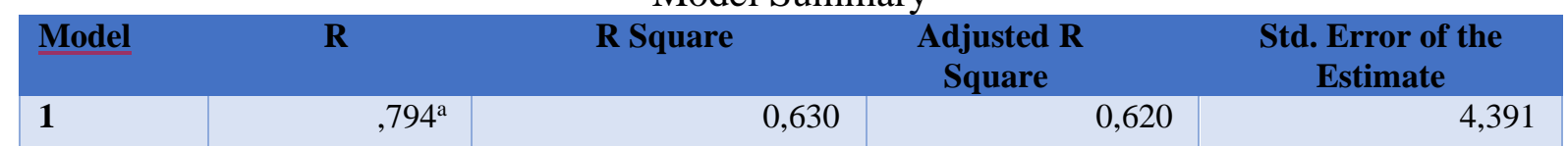

a. Predictors: (Constant), Disiplin_Belajar

Koefisien korelasi (R) sebesar 0,794 menunjukkan hubungan yang kuat antara variabel Disiplin Belajar dengan variabel Kemampuan Memecahkan Soal Cerita Matematika. Koefisien determinasi $\left(\mathrm{R}^{2}\right)$ sebesar 0,630 memberi pengertian bahwa 63,0\% Variabel Kemampuan Memecahkan Soal Cerita Matematika ditentukan oleh Variabel Disiplin Belajar , dan sisanya ditentukan oleh faktor lain. Std. Error of the Estimate merupakan kesalahan standar dari perkiraan yang bernilai 4,391. Dan nilai determinasi jauh dibawah standar kesalahan yang berarti koefisien korelasi Disiplin Belajar dan Kemampuan Memecahkan Soal Cerita Matematika terdapat hubungan yang kuat.

Kemudian dilanjutkan dengan uji regresi Disiplin Belajar dengan Kemampuan Memecahkan Soal Cerita Matematika melalui suatu persamaan dibawah ini: 
Tabel 4. Persamaan Garis Regresi Disiplin Belajar Dengan Kemampuan Memecahkan Soal Cerita Matematika

\section{Coefficients $^{\mathbf{a}}$}

\begin{tabular}{|c|c|c|c|c|c|c|}
\hline \multirow{2}{*}{\multicolumn{2}{|c|}{ Model }} & \multicolumn{2}{|c|}{$\begin{array}{l}\text { Unstandardized } \\
\text { Coefficients }\end{array}$} & \multirow{2}{*}{$\begin{array}{l}\text { Standardized } \\
\text { Coefficients } \\
\text { Beta }\end{array}$} & \multirow[t]{2}{*}{$\mathbf{t}$} & \multirow[t]{2}{*}{ Sig. } \\
\hline & & B & Std. Error & & & \\
\hline 1 & (Constant) & 22,428 & 4,110 & & 5,457 & 0,000 \\
\hline & Disiplin_Belajar & 1,086 & 0,137 & 0,794 & 7,936 & 0,000 \\
\hline
\end{tabular}

a. Dependent Variable: Kemampuan_Memecahkan_Soal_Cerita_Matematik

Berdasarkan tablel di atas maka didapatkan persamaan regresinya yaitu : $Y^{\wedge}=22,428+1,086$ $\mathrm{X}_{1}$ Dari persamaan regresi tersebut diatas diketahui bahwa koefisien regresi $\left(\mathrm{b}_{1}\right)$ sebesar 1,086. Hal ini menunjukan besarnya Hubungan Disiplin Belajar dengan Kemampuan Memecahkan Soal Cerita Matematika. Karena Hubungan tersebut bersifat positif, maka apabila variabel Disiplin Belajar $\left(\mathrm{X}_{1}\right)$ mengalami peningkatan, maka peningkatan tersebut akan diimbangi dengan peningkatan pada variabel Kemampuan Memecahkan Soal Cerita Matematika. Selanjutnya uji hipotesis Hubungan variabel bebas $\mathrm{X}_{1}$ dengan variabel terikat $\mathrm{Y}$ adalah dengan membandingkan antara $t_{\text {hitung }}$ dengan $t_{\text {tabel }}$. Kriteria pengujiannya adalah apabila $t_{\text {hitung }}>t_{\text {tabel }}$ maka $\mathrm{H}_{0}$ ditolak dan $\mathrm{H}_{1}$ diterima. Sebaliknya apabila $\mathrm{t}_{\text {hitung }}<\mathrm{t}_{\text {tabel }}$, maka $\mathrm{H}_{0}$ diterima dan $\mathrm{H}_{1}$ ditolak. Dengan melihat hasil dari model persamaan regresi di atas, maka untuk menguji keberartian dari nilai koefisien regresi untuk variabel Disiplin Belajar dapat digunakan dengan Uji-t, nilai $t_{\text {hitung }}$ yang diperoleh yaitu sebesar 7,936 sedangkan t tabel yaitu sebesar 0,680. Sehingga $t_{\text {hitung }}>t_{\text {tabel }}$, maka hasil ini menunjukkan terdapat Hubungan variabel Disiplin Belajar dengan variabel Kemampuan Memecahkan Soal Cerita Matematika.

\section{Hubungan Disiplin Belajar dan Bimbingan Belajar secara Bersamasama dengan Kemampuan Memecahkan Soal Cerita Matematika}

Tabel 5 Metode Enter Variables Entered/Removed ${ }^{a}$

\begin{tabular}{|c|c|c|c|}
\hline Model & Variables Entered & Variables Removed & Method \\
\hline 1 & $\begin{array}{c}\text { Bimbingan_Belajar, } \\
\text { Disiplin_Belajar }^{\mathrm{b}}\end{array}$ & & Enter \\
\hline
\end{tabular}

aDependent Variable: Kemampuan_menyelesaikan_Soal_Cerita_Matematika

${ }^{\mathrm{b}}$ All requested variables entered.

Metode yang juga digunakan dalam regresi ini adalah metode enter, artinya adalah semua variabel bebas yaitu Bimbingan Belajar dan Disiplin Belajar dimasukkan tanpa memandang apakah variabel tersebut berhubungan besar atau kecil dengan variabel terikat yaitu Kemampuan Memecahkan Soal Cerita Matematika 
Tabel 6. Nilai Koefisien Korelasi dan Determinasi Bimbingan Belajar dan Disiplin Belajar secara bersama-sama

Model Summary ${ }^{b}$

\begin{tabular}{|c|c|c|c|c|}
\hline Model & $\mathbf{R}$ & R Square & $\begin{array}{l}\text { Adjusted R } \\
\text { Square }\end{array}$ & $\begin{array}{l}\text { Std. Error of the } \\
\text { Estimate }\end{array}$ \\
\hline 1 & ,899 & 0,808 & 0,797 & 3,207 \\
\hline
\end{tabular}

\section{Kemampuan menyelesaikan Soal Cerita_Matematika}

Diketahui koefisien korelasi (R) sebesar 0,899 menunjukkan hubungan yang sangat kuat antara variabel bebas (Bimbingan Belajar dan Disiplin Belajar) dengan variabel terikat (Kemampuan Memecahkan Soal Cerita Matematika). Koefisien determinasi $\left(\mathrm{R}^{2}\right)$ sebesar 0,808 memberi pengertian bahwa 80,8 \% Kemampuan Memecahkan Soal Cerita Matematika ditentukan oleh Bimbingan Belajar dan Disiplin Belajar dan lalu sisanya ditentukan oleh faktor lain.

Adjusted $\mathrm{R}$ square merupakan nilai $\mathrm{R}^{2}$ yaitu nilai yang disesuaikan sehingga baganannya lebih mendekati mutu kebenaran pada model dalam populasi. Std. Error of the Estimate merupakan kesalahan standar dari penaksiran dan bernilai 3,207 untuk lebih jelasnya dapat dilihat dari Tabel 4.4.6 Anova dibawah ini :

Tabel 7 Tabel Anove Anova $^{\mathrm{a}}$

\begin{tabular}{|l|r|r|r|r|r|}
\hline Model & Sum of Squares & df & \multicolumn{1}{c|}{$\begin{array}{c}\text { Mean } \\
\text { Square }\end{array}$} & F & \multicolumn{1}{|c|}{ Sig. } \\
\hline $\mathbf{1}$ Regression & 1557,293 & 2 & 778,646 & 75,699 &, $000^{\mathrm{b}}$ \\
\hline Residual & 370,297 & 36 & 10,286 & & \\
\hline Total & 1927,590 & 38 & & & \\
\hline
\end{tabular}

a. Dependent Variable: Kemampuan_menyelesaikan_Soal_Cerita_Matematika

b. Predictors: (Constant), Bimbingan_Belajar, Disiplin_Belajar

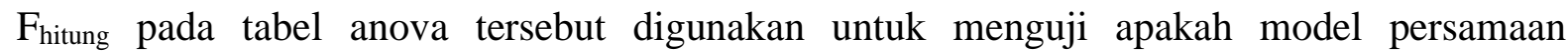
$\mathrm{Y}=\mathrm{a}+\mathrm{b}_{1} \mathrm{X}_{1}+\mathrm{b}_{2} \mathrm{X}_{2}$ yang diajukan dapat diterima atau tidak. Caranya dengan membandingkan $F_{\text {hitung }}$ dengan $F_{\text {tabel. }}$ Jika $F_{\text {hitung }}>F_{\text {tabel }}$ maka model diatas dapat diterima.

$F_{\text {hitung }}=75,699$ dan $F_{\text {tabel }}=3,26$ (dari tabel $F$ ) sehingga $F_{\text {hitung }}>F_{\text {tabel }}$ maka model persamaan $\mathrm{Y}=\mathrm{a}+\mathrm{b}_{1} \mathrm{X}_{1}+\mathrm{b}_{2} \mathrm{X}_{2}$ yang digunakan dapat diterima. Atau dengan melihat probabilitasnya, terlihat bahwa probabilitasnya adalah $0,00<0,05$ sehingga signifikan, maka dapat disimpulkan bahwa model persamaan $\mathrm{Y}=\mathrm{a}+\mathrm{b}_{1} \mathrm{X}_{1}+\mathrm{b}_{2} \mathrm{X}_{2}$ yang digunakan dapat diterima. 
Tabel 8. Persamaan Garis Regresi $X_{1}$ dan $X_{2}$ dengan $Y$ Coefficients $^{\mathrm{a}}$

\begin{tabular}{|c|c|c|c|c|c|c|}
\hline \multirow{2}{*}{\multicolumn{2}{|c|}{ Model }} & \multicolumn{2}{|c|}{$\begin{array}{l}\text { Unstandardized } \\
\text { Coefficients }\end{array}$} & \multirow{2}{*}{$\begin{array}{l}\text { Standardized } \\
\text { Coefficients } \\
\text { Beta }\end{array}$} & \multirow[t]{2}{*}{ t } & \multirow[t]{2}{*}{ Sig. } \\
\hline & & B & Std. Error & & & \\
\hline 1 & (Constant) & 12,091 & 3,495 & & 3,459 & 0,001 \\
\hline & Disiplin_Belajar & 0,368 & 0,160 & 0,269 & 2,304 & 0,027 \\
\hline & Bimbingan Belajar & 1,069 & 0,185 & 0,673 & 5,775 & 0,000 \\
\hline
\end{tabular}

a. Dependent Variable: Kemampuan menyelesaikan Soal Cerita_Matematika

Uji t digunakan untuk menguji signifikansi konstanta dari setiap variabel bebas, dengan hipotesis :

$\mathrm{H}_{0}$ : variabel bebas (Bimbingan Belajar dan Disiplin Belajar) secara bersama-sama berhubungan dengan variabel terikat (Kemampuan Memecahkan Soal Cerita Matematika )

$\mathrm{H}_{1}$ : variabel bebas (Bimbingan Belajar dan Disiplin Belajar) secara bersama-sama tidak berhubungan dengan variabel terikat

\section{Kemampuan Memecahkan Soal Cerita Matematika}

Kemudian thitung dibandingkan dengan $t_{\text {tabel }}$ dan diperoleh Untuk variabel Bimbingan Belajar $t_{\text {hitung }}>\mathrm{t}_{\text {tabel }}(11,439>0,680)$ maka $\mathrm{H}_{0}$ ditolak, artinya variabel Kemampuan Memecahkan Soal Cerita Matematika dihubungkan oleh variabel Bimbingan Belajar. untuk variabel Disiplin Belajar $t_{\text {hitung }}>\mathrm{t}_{\text {tabel }}$ atau $(7,936>0,680)$ maka $\mathrm{H}_{0}$ ditolak, artinya variabel Kemampuan Memecahkan Soal Cerita Matematika dihubungkan oleh variabel Disipling Belajar. Dari tabel 4.4.7 diperoleh nilai persamaan regresinya adalah sebagai berikut: $\hat{Y}=12,091+1,069 \mathrm{X}_{2}+$ $0,368 \mathrm{X}_{1}$.

\section{PEMBAHASAN}

Berdasarkan hasil pengujian hipotesis diketahui bahwa dengan peningkatan Bimbingan Belajar dapat berhubungan positif dengan peningkatan Kemampuan Memecahkan Soal Cerita Matematika pada siswa kelas VI di SDN 2 Muara Ciujung Barat a. Uji Hipotesis 1

Untuk hipotesis pertama dalam penelitian ini adalah menolak $\mathrm{H}_{0}$ dan menerima $\mathrm{H}_{1}$, artinya nilai koefisien regresi dan variabel Bimbingan Belajar memiliki persamaan regresi tidak sama dengan nol. Sehingga dapat disimpulkan bahwa variabel Bimbingan Belajar mempunyai hubungan yang positif dan signifikan dengan variabel Kemampuan Memecahkan Soal Cerita Matematika.

\section{Uji Hipotesis 2}

Nilai R (koefisien korelasi) sebesar 0,749 menunjukkan hubungan yang sangat kuat variabel Disiplin Belajar dengan Kemampuan Memecahkan Soal Cerita Matematika. Kemudian nilai koefisien determinasi $\left(\mathrm{R}^{2}\right)$ maka kemampuan Memecahkan Soal Cerita Matematika pada siswa kelas VI di SDN 2 Muara Ciujung Barat dihubungkan dan ditentukan oleh Disiplin Belajar, sedangkan sisanya ditentukan oleh faktor lain.

\section{Uji Hipotesis 3}

Berdasarkan hasil analisis data dan uji hipotesis pada penelitian ini dapat disimpulkan bahwa Disiplin Belajar dan Bimbingan Belajar sama-sama memiliki hubungan yang positif dan signifikan. Hal ini berarti hubungan Disiplin Belajar dan Bimbingan Belajar secara bersama- 
sama dengan Kemampuan Memecahkan Soal Cerita Matematika pada siswa kelas VI di SDN 2 Muara Ciujung Barat dapat dinyatakan berhasil.

\section{KESIMPULAN DAN SARAN}

Berdasarkan data-data hasil penelitian dan pembahasan mengenai tentang Hubungan bimbingan belajar dan disiplin belajar terhadap kemampuan memecahkan soal cerita Matematika Kelas VI di SDN 2 Muara Ciujung Barat, maka kesimpulan dari penelitian ini adalah sebagai berikut :

1. Terdapat hubungan yang sangat kuat dan positif Bimbingan Belajar dengan Kemampuan Memecahkan Soal Cerita Matematika pada siswa kelas VI di SDN 2 Muara Ciujung Barat dihubungkan dan ditentukan oleh Bimbingan Belajar, sedangkan sisanya ditentukan oleh faktor lain.

2. Terdapat hubungan yang sangat kuat dan positif Disiplin Belajar dengan Kemampuan Memecahkan Soal Cerita Matematika pada siswa kelas VI di SDN 2 Muara Ciujung Barat dihubungkan dan ditentukan oleh Disiplin Belajar, sedangkan sisanya ditentukan oleh faktor lain.

3. Terdapat hubungan yang kuat dan positif bimbingan belajar dan disiplin belajar secara bersama-sama dengan kemampuan memecahkan soal cerita Matematika Kelas VI di SDN 2 Muara Ciujung Barat sedangkan siswanya ditentukan oleh faktor lain.

\section{DAFTAR PUSTAKA}

Adilla, J.S. (2017). "Hubungan Disiplin dan Motivasi Kerja Terhadap Kinerja Guru Pada SMAN 1 Canduang Kabupaten

Agam". (Jurnal Sosial dan Ilmu Ekonomi. Vol. 1. No. 02).

Wibowo, A. (2012). Pendidikan Karakter. Yogyakarta: Pustaka Belajar

Ahmadi dan Supriyono (2013). Psikologi Belajar. Jakarta: PT. Rineka Cipta

Aisyah (2015). Perkembangan Peserta Didik dan Bimbingan Belajar, Yogyakarta Deepublish

Anni, Catharina Tri dan Achmad Rifa'i. 2011. Psikologi Pendidikan. Semarang: UNNES Press.

Prihandoko, A.C. (2006). Memahami Konsep Matematika Secara Benar Dan Menyajikannya Dengan Menarik. Jakarta: Depdiknas.

(2008). Bahan Ajar Cetak: Pemecahan Masalah Matematika. Direktorat Jendral Pendidikan

Tinggi: Departemen Pendidikan Nasional

Darma, S. (2008). Penulisan Modul. Jakarta: Direktorat Tenaga Kependidikan Direktorat Jendral Peningkatan Mutu Pendidik dan Tenaga Kependidikan Departemen Pendidikan Nasional

Lestari, E., Karunia dan Yudhanegara, M.R. (2015). Penelitian Pendidikan Matematika. Bandung: PT Refika Aditama.

Gunarsa, Y.S.D. dan Gunarsa, S.D. (1981). Psikologi Remaja. Jakarta: BPK Gunung Agung. Irham \& Wiyani. (2014). Psikologi Pendidikan: Teori dan Aplikasi dalam Proses Pembelajaran. Jogjakarta: Ar-Ruzz

Karso, et.al.. (2011). Pendidikan Matematika I . Jakarta:Universitas Terbuka.

Karso (2007). Pendidikan Matematika.Jakarta: Universitas Terbuka.

Mamede, E. (2010). Issues On Children's Ideas Of Fractions When Quotient Interpretation Is Used. 1-20.

Mugiarso, H, et.al. (2004). Bimbingan dan Konseling. Semarang: Universitas Negeri Semarang Press.

Mulyasa, (2013). Pengembangan dan implentasi pemikiran kurikulum.Bandung: Rosdakarya 
Peraturan Pemerintah Republik Indonesia Nomor 47 Tahun 2008 Tentang Wajib Belajar Peraturan Pemerintah Republik Indonesia Nomor 13 Tahun 2015 Tentang Perubahan Kedua Atas Peraturan Pemerintah Nomor 19 Tahun 2005 Tentang Standar Nasional Pendidikan

Peraturan Daerah (Perda) Kabupaten Lebak Nomor 3 Tahun 2019 tentang Perubahan Atas Peraturan Daerah Nomor 2 Tahun 2010 Tentang Penyelenggaraan Pendidikan Di Kabupaten Lebak.

Profil SD Negeri 2 Muara Ciujung Barat Kecamatan Rangkasbitung Kabupaten Lebak Tahun 2020.

Wayan, P. Kristiantari, R. dan Putra, S. (2014). Hubungan Bimbingan Belajar Orang Tua dan Konsep Diri dengan Hasil

Belajar Matematika Siswa Kelas V SD Gugus V Tampaksiring. MIMBAR PGSD Universitas Pendidikan Ganesha Jurusan PGSD. Vol. 2 (1), Hlm. 1-3. Diakses pada 23 November $2015 \mathrm{http}$ ://id.portalgaruda.org/?ref=browse \&mod=viewarticle \&article=304074).

Purwanto. (2014). Evaluasi Hasil Belajar. Yogyakarta: Pustaka Pelajar.

Rahardjo, M dan Waluyati. A. (2011). Pembelajaran Soal Cerita Operasi Hitung Campuran di Sekolah Dasar. Yogyakarta : Pusat Pengembangan dan Pemberdayaan Pendidik dan Tenaga Kependidikan Matematika.

Singarimbun, M. dan Effendi, S. (1995). Metode Penelitian Survey. Jakarta: LP3ES.

Sugiyono. (2014). Metode Penelitian Pendidikan Pendekatan Kuantitatif, Kualitatif, dan $R \& D$. Bandung: Alfabeta

Sugiyono. 2012. Metode Penelitian Kuantitatif Kualitatif dan R\&B. Bandung: Alfabeta.

UU 20 Tahun 2003 tentang Sistem Pendidikan Nasional

Van De Wale, J. A. (2006). Pengembangan pengajaran matematika sekolah dasar dan menengah. Jilid I. Edisi keenam. Jakarta: Erlangga. 